\title{
Reduction of Diameter of Hair Shaft among Women with Hirsutism
}

\author{
Selwa Elias Yacoub \\ Community Medicine Department, Al Kindy College of Medicine \\ University of Baghdad, Baghdad, Iraq \\ E-mail: drselwa56@yahoo.com
}

Received: July 28, 2010 Accepted: August 13, 2010 doi:10.5539/gjhs.v3n1p135

\begin{abstract}
Hirsutism is a common endocrinological disorder and extremely distressing cosmetic condition in women, most often caused by increased production of androgen or peripheral hypersensitivity to normal androgen circulating levels. To evaluate the efficacy of spironolactone (aldactone) alone or in combination with oral contraceptive pills and /or metformin in the treatment of hirsute patients a prospective study had been conducted at the specialized clinic of endocrinology/ outpatient department, Baghdad teaching hospital, for the period from July 2006 to January 2008. A six month follow up revealed a significant reduction in the diameter of hair shaft among hirsute women using aldactone alone or aldactone combined with oral contraceptive pills, $44.49 \%$ and $42.85 \%$ respectively after 3 month of treatment. Six months treatment yield a statistically significant reduction in the hair shaft diameter with the optimum effect among women received aldactone combined with oral contraceptive pills achieving reduction of $60 \%$, aldactone alone give a reduction of $52.49 \%$, aldactone combined with metformin also result in a reduction of $51.2 \%$ while women using aldactone combined with oral contraceptive pills and metformin found to have the minimal effect $37.5 \%$ reduction. Aldactone as an antiandrogenic drug seem to induce an objectively estimated effect manifested in the percentage of reduction in mean diameter of hair shaft among hirsute patients if it is used alone or in combination with oral contraceptive pills and or metformin
\end{abstract}

Keywords: Hirsutism, Hair shaft diameter, Aldactone, Oral contraceptive pills, Metformin

\section{Introduction}

Hirsutism is the presence of excessive coarse terminal hairs in the female in a male like pattern, in specific androgen - sensitive area of the body, it is a common disorder affecting between $5 \%$ to $15 \%$ of women (Ricardio, 2003; Nadia \& Peter, 2006; Spritzer et al., 2000; Mellissa \& Peter, 2003).

Female Hirsutism is a medical problem that can have significant psychological consequences. most women seek treatment for hirsutism for cosmetic condition, because excess body hair outside cultural norms can be very distressing (Ricardio, 2003; Nadia \& Peter, 2006; Mellissa \& Peter, 2003; Brown et al., 2009) Hirsutism may be a sign of an underlying endocrine abnormality, it can result from an overproduction of androgen, or a sign of increased sensitivity of hair follicles (pilosebaceous unit) to normal levels of circulating androgen or both of them (Spritzer et al., 2000; Mellissa \& Peter, 2003; Karakurt et al., 2008). The main sources of androgens in women are the ovaries, adrenal glands and peripheral adipose tissues (Nadia \& Peter, 2006).

Treatment options for patients who have hirsutism can be divided into those targeting local manifestations of hirsutism and pharmacologic therapy aimed at the underlying causes. Local therapy includes physical methods of hair removal such as shaving, bleaching, depilatories, and electrolysis, laser therapy, topical treatment (Mellissa $\&$ Peter, 2003).

The systemic therapies include glucocorticoids, oral contraceptives (OCs), spironolactone, flutamide, finasteride, cyproterone acetate and insulin sensitizers (metformin) (George, 2009). For women with idiopathic hirsutism,polycystic ovary syndrome (PCOS), or late onset congenital adrenal hyperplasia (CAH), appropriate treatment decisions depend on each patients desires and childbearing plans (Mellissa \& Peter, 2003).

The anti-androgen drugs are frequently chosen for treatment of hirsutisim without concern of it's aetiology (Spritzer et al., 2000), Spironolactone (aldactone) is one of the most commonly and widely used therapy for hirsutism, it is an aldosterone antagonist which was used initially as a potassium-sparing diuretic, it has antiandrogenic properties (Nadia \& Peter, 2006), a daily doses of 50-200 mg /day blocks androgen receptors, also it decrease testosterone production making it effective for hirsutism (George, 2009). Although the general effectiveness of this drug had been confirmed, extended clinical trials with this drug had produced variable 
results (Spritzer et al., 2000). Safety, availability, and low cost of spironolactone is related to its widely use (Nadia \& Peter, 2006; Mellissa \& Peter, 2003)

PCOS related hirsutism is associated with anovulation, increased ovarian androgen, hyperinsulineamia and or insulin resistance. Therefore anti-androgen may inhibit hirsutism in PCOS patients (Spritzer et al., 2000). Combined oral contraceptives OCs effectively and most widely used to suppress ovarian androgen production and are now considered the first line of treatment for young women with hirsutism who don't want to become pregnant (Nadia \& Peter, 2006; George, 2009; Cem \& Iptisam, 2006), their progestational activity lowers lutinizing hormone (LH) and thus LH- mediated ovarian androgen release. The beneficial effect of the estrogenic component is mainly attributable to its sex hormone binding globulin (SHBG) elevating ability which decrease the amount of free testosterone (Cem \& Iptisam, 2006)

In PCOS patients with the presence of obesity and or metabolic disturbances the use of insulin - sensitizing agents may be useful, metformin (Glucophage) has shown to improve insulin sensitivity and decrease testosterone levels (Nadia \& Peter, 2006; Spritzer et al., 2000; Mellissa \& Peter, 2003)

Response to pharmacologic agents in reducing hirsutism is slow, occurring over many months (Mellissa \& Peter, 2003), six months to a year of therapy is usually required before results are noticeable (George, 2009). The diameter of the hair are increased in hirsute women and reduced with antiandrogen treatment (George Kovalevsky et al., 2010)

Till now a debate still present regarding the efficacy of aldactone in the treatment of hirsutism whether it is used alone or in combination with other drugs specifically used for the management of the underlying endocrinological causes. This study had been conducted to evaluate the efficacy of using spironolactone alone or in combination with oral contraceptive pills (OCs), and or metformin in the treatment of hirsute patients, reflected on the reduction of diameter of hair shaft as an objective indicator.

\section{Patients and methods}

A prospective study had been conducted at the clinic of endocrinology / outpatient department / Baghdad teaching hospital /Baghdad, for the period from July 2006 to January 2008, A convenient sample of 42 female attending the clinic of endocrinology, diagnosed to have hirsutism, irrespectively of their underlying cause, and accepted to participate in the study had been enrolled. The bases of recruitment restricted to those Patients who had been defined to have clinically significant hirsutism, with a score of 8 or more of overall 36 scale, according to Ferriman - Gallawy scoring system which assess the growth of coarse hair in each of the 9 androgen sensitive body area (upper lips, chin, chest, upper and lower back, abdomen, arm, forearm, thigh, and leg) on a scale of 0 to 4 (George, 2009). Inclusion criteria:

- Age between 18 and 40 years

- Duration of hirsutism $>2$ years

- Had not received any medical treatment for hirsutism for the last 6 months

- Using the same mechanical method of hair removal (a traditionally known method in Iraq by using a thread).

A questionnaire was formulated and completed through an interview for every patient in the studied sample by the investigator. The questionnaire include information about age, marital status, family history of hirsutism (among the first relatives), duration of hirsutism Anthropometric measurement; weight with indoor clothes using a digital weight scale (Seca, Australia) each time the scale was calibrated and the weight was measured to the nearest fraction of $\mathrm{Kg}$ (to the nearest $0.1 \mathrm{~kg}$ ), and height was measured using the standing height measurement (CMS weighing equipment LTD, England), the patient stood shoeless with the heels and the back in contact with the vertical column of the scale. BMI was calculated from the formula weight $/$ height $^{2}$ (using metric units, $\mathrm{kg} / \mathrm{m}^{2}$ ) (Graham, 2009).

Serum testosterone level had been estimated for all participant at their initial visit using double - antibody radioimmunoassay (CIS bio-international-Fance, Filiate de Shering S.A) method

Medical (pharmacological) treatment had been already assigned for each patient by the consultant of endocrinology according to their underlying medical condition without the interference of the investigator, all the medications were delivered monthly for all the participants freely (without payment); Aldactone (Searl), Metformin (Menarini international), and Oral contraceptive pills (OCs), microgynon 30(Schering health) The patients involved in the study were divided into 4 groups according to the plan of treatment:

I - Aldactone 
II - Aldactone + metformin

III - Aldactone + OCs

IV -Aldactone + metformin + OCs

The dose of aldactone used for all the participant was $100 \mathrm{mg} /$ day (50 $\mathrm{mg}$ twice daily). Metformin was used in a dose of $1500 \mathrm{mg}$ daily (in three divided doses of $500 \mathrm{mg}$ ). One pill of OCs (Microgynon 30) had been used daily for 21 successive days and repeated after 7 days tablet free interval (during which withdrawal bleeding occur), each tablet containing ethinylestradiol $30 \mathrm{mg}$ and levonogestrel $150 \mathrm{mg}$.

At time of recruitment Hirsutism was evaluated subjectively by Ferriman - Gallway scoring system, at initial visit only, and objectively by measurement of the mean diameter of hair shaft which undertaken as a baseline reading for further follow up assessment (Falsetti et al., 1997)

\subsection{Measurement of diameter of hair shaft}

The method used for measurement of mean diameter of hair shaft in this study was as follow:

The patients were told to leave their hair on the chin to grow for at least 10 days (without mechanical removal), three of the thickest hair were selected and plucked using a tweezers, and the thickest diameter of the selected hairs were measured using a micrometer applied to an optical light microscope (using the power $1 / 10$ ) then the mean of these three reading was calculated and used as an indicator for estimation the effect of different plans of treatment (Falsetti et al., 1997; Van\& Le Roux, 2003).

\subsection{Follow up}

Follow up was continued for 6 months for all patients included in the study. Monthly visit was arranged and had achieved for all of them without interruption during which confirmation of the intake of recommended medication was done by checking the empty sheets of medication. Measurement of mean diameter of hair shaft was done after 3 months and 6 months of treatment

\subsection{Statistical analysis}

All data had been collected and introduced into a personal computer and analyzed using Minitab package version 13.Descriptive analysis were completed using percentages, means with their standard deviation ( $\mathrm{Sd}$ ). ANOVA test had been used to estimate the statistical differences in the mean diameter of hair shaft among and within different groups at baseline, 3months and 6 months after treatment. on other hand the percentage of reduction in the mean diameter of hair shaft with its $95 \%$ confidence interval (CI) among each group to determine the effect of each plane of treatment separately after 3 months and 6 months in comparison to baseline was done using Two way student $t$-test. Statistical differences with $p$ value of $\leq 0.05$ regarded to be significant.

\section{Results}

Most of the patients in the studied sample were unmarried representing $80.95 \%$, and $57.14 \%$ of them had family history of hirsutism (table 1), with mean age (27.7 years, Sd 5.12), mean BMI (28.9 kg/ m², Sd 6.97), and mean duration of hirsutism (7.76 years, Sd 4.90), mean score of hitrsutism (14.95, Sd 7.73), and mean blood testosterone level (3.22 ngm / ml, Sd 1.38), (table 2)

The percentage of patients among each group, according to the plan of treatment recommended for them (table 3 ) were $28.57 \%(n=12)$ group I (aldactone), $19.05 \%(n=8)$ group II (Aldactone + metformin), $38.10 \%(n=16)$ group III (Aldactone + OCs) and 14.28\% $(\mathrm{n}=6)$ group IV (Aldactone + metformin + OCs).

No statistical differences (table 4) had been found among the four studied groups in regard to the mean diameter of their hair shaft, neither at baseline measurement ( $\mathrm{p}$ value 0.559 ), nor that following treatment, after 3 month ( $\mathrm{p}$ value 0.446 ) or after 6 months ( $\mathrm{p}$ value 0.064 )

On the other hand a very highly statistical significant difference had been found ( $p$ value 0.000 ) in the mean diameter of hair shaft of all the studied groups, after 3 months and 6 months of applying the 4 different plans of treatment in comparison to their baseline mean diameter (table5)

Although the percentage of reduction of diameter of hair shaft after 3 months treatment (table 6) was statistically significant among group I (p value 0.000 ), a reduction of $44.49 \%$ with $95 \%$ confidence interval CI $(18.39 ; 41.61)$ and group III (p value 0.000$)$, a reduction of $42.85 \%$ with $95 \%$ CI $(15.90 ; 35.85)$, the percentage of reduction was statistically not significant among group II and group IV.

All groups in the studied sample had shown a statistically significant reduction in the diameter of hair shaft after 6 months of treatment compared with baseline measurement, and the highest percentage found to be among 
group III, a reduction of $60 \%$ with $95 \%$ CI $(27.35 ; 46.15)$, followed by group I, a reduction of $52.49 \%$ with $95 \%$ confidence interval $(22.98 ; 47.02)$, then group II, a reduction of $51.2 \%$ with $95 \%$ CI $(10.80 ; 54.20)$ and finally group IV, a reduction of $37.5 \%$ with $95 \% \mathrm{CI}(9.50 ; 30.50)$, (table 7$)$

\section{Discussion}

Spironolactone (aldactone or spirotone) is an antiandrogen, generally lowers the plasma testosterone by altering its formation and metabolism as well as by decreasing its blood production rate (Tremblay, 1986), which can be taken with or without the oral contraceptive pill to reduce hirsutism (Brown et al., 2009),. insulin sensitizers particularly metformin are being used increasingly with very promising results in hirsute women with PCOS and when used with antiandrogen treatment, may have additive benefits on insulin sensitivity and hyperandrogenaemia compared with monotherapy ((Nadia \& Peter, 2006).

A Cochrane review 2009 ((Brown et al., 2009) of nine randomized controlled intervention, two trials that compared 6 months treatment of $100 \mathrm{mg} / \mathrm{d}$ of spironolactone with placebo was associated with a statistically significant subjective improvement in hair growth and a decrease in Ferriman-Gallway scores (F-G), similar finding also had been revealed in other studies conducted by (Karakurt et al., 2008) and a study conducted by Poll Mara (Spritzer et al., 2000) using the same subjective clinical parameter.

The variability of the approaches used for assessment the effectiveness of aldactone alone or in combination with OCs and or metformin, in the treatment of hirsute women being objective, measurement of the diameter of hair shaft, in this study which expected to be more precise than the entirely subjective assessment, Ferriman- Gallway scoring scales which had wide inter- observer variation (Brown et al., 2009), and had been used mostly in previous trials and studies, made it difficult to establish a systematic comparability between the statistical results being reached accordingly.

The current study had demonstrated that 6 months treatment with 100mg aldactone yield a statistical significant reduction in the hair shaft diameter whether it was used alone or in combination with either OCs and /or metformin

A six month follow up of 12 hirsute women treated with $100 \mathrm{mg}$ aldactone alone in the studied sample, had revealed $44.49 \%$ reduction of hair shaft diameter, with 95\% confidence interval (CI) [ 18.39;41.61 ], and 52.49\% with CI $(22.98 ; 47.02)$ respectively after 3 months and 6 months., In a study conducted in Italy by Moghetti et al., (2000) also had confirmed a reduction of hair diameter of 10 hirsute women treated with $100 \mathrm{mg} / \mathrm{d}$ of aldactone alone after 6 months treatment with mean change (+/- SEM, $-11.7+/-5.6 \%)$.

The use of aldactone in combination with OCs assigned for 16 patients in the current study lead to reduction in the diameter of hair shaft $42.85 \%$ with $95 \%$ CI $(15.90 ; 35.85)$ after 3 months and an optimum reduction of $60 \%$ with $95 \%$ CI $(27.35$; 46.15) after 6months treatment. The use of combination of oral contraceptive pills with aldactone had been shown to reduce hair shaft diameter in menstruating women (Croxatto et al., 1983), and according to Mellissa $\mathrm{H}$. Hunter up to $75 \%$ of women report clinical improvement with combination therapy of aldactone and OCs (Mellissa \& Peter, 2003).

While the combination of aldactone with metformin in our study lead to a reduction of 51.2 with $95 \% \mathrm{CI}(10.80$; 54.20) after 6 months of treatment, Kelly and Gordon demonstrated significant improvement in hirsutism in women with PCOS after 6 months treatment with metformin compared with placebo(Kelly \& Gordon, 2002)

The combination of aldactone, metformin and OCs in this study result in a minimum reduction of only $37.5 \%$ with $95 \% \mathrm{CI}(9.50 ; 30.50)$ after 6 months treatment which may be explained by the limited number of patients only 6 , had received this treatment.

The results already had been reached in this study enhance the freedom of choice of recommended treatment for hirsute patients according to their underlying causes, using either aldactone alone or in combination with OCs and or insulin sensitizers (metformin) for at least 6 months to reach the ultimate aim of reducing the growth of coarse hair.

More studies and trials need to be conducted and preferably using one of the objective indicators, hair shaft diameter being one of them, rather than the subjective ones, to assess the effectiveness of different plans of treatment known to be used to reduce the hair growth in hirsute women which is one of the more promising affairs to encounter this problem and ultimately diminish the psychological and social burden of one of the most embarrassing and distressing condition may a women face, with an overall purpose of improving the quality of adult life. 


\section{References}

Brown J, Farquhar C, Lee O, Toomath R, \& Jepson RG. (2009). Spironolactone versus placebo or in combination with steroids for hirsutism and / or acne.The.Cochrane Library 2009, Apr 15; (2), [Online] Available: http://www.thecochranelibrary.com

Cem Batukan, M.D., \& Iptisam Ipek Muderris, M.D. (2006). Efficacy of a new oral contraceptive containing drospirenone and ethinyl estradiol in the long-term treatment of hirsutism. Fertility and Sterility, Vol.85, No.2: 436- 440 .

Croxatto HB, Diaz S, Robertson DN, \& Pavez M. (1983). Clinical chemistry in women treated with levonorgestrel implants (Norplant) or TCu 200 IUD. Contraception, 27: 281-8.

Falsetti L, De Fusco D., Eleftheriou G, \& Rosina B. (1997). Treatment of hirsutism by finasteride and flutamide in women with polycystic ovary syndrome. Gynecol Endocrinol, 11 (4): 251-7 (ISSN: 0951-3590)

George Kovalevsky, M.D., Susan A. Ballagh, M.D., Frank Z.Stanczyk. Ph. D., Jennifer Lee, B.S., Joann Cooper, B.S., and David F, \& Archer, M.D. (2010). Levonorgestel effects on serum androgens, sex hormone- binding globulin levels, hair shaft diameter, and sexual function. Fertility and Sterility, 93 (6): 1997-2003.

George T Griffing, MD. (2009). Hirsutism. [Online] Available: http//emedicine medscape.com/article/121038, updated (Aug 14, 2009).

Graham Douglas, \& John S. Bevan. (2009). The general examination. In. Graham Douglas, Fiona Nicol, \& Colin Robertson (Eds). Macleod 's clinical examination (12 ${ }^{\text {th }}$ Edition). International: Churchill Livingstone, (chap 3) pp 46-67.

Karakurt F, Sahin I, Güler S, Demirbas B, Culha C, Serter R, Aral Y, \& Bavbek N. (2008). Comparison of the clinical efficacy of flutamide and spironolactone plus ethinyloestradiol / cyproterone acetate in the treatment of hirsutism: a randomized controlled study. Adv Ther. Apr, 25 (4): 321-8.

Kelly CI, Gordon D. (2002). The effect of metformin on hirsutism in polycystic ovary syndrome. Eur $J$ Endocrinol, 147: 217-21.

Mellissa H. Hunter, M.D., and Peter J. \& Carek, M.D. (2003). Evaluation and Treatment of Women with Hirsutism. American Family Physician, 67 (12): 2565-2572.

Moghetti P, Tosi F, Tosti A Negri C, Misciali C, Perrone F, Caputo M, Muggeo M, \& Castello R. (2000). Comparison of spironolactone, flutamide and finasteride efficacy in the treatment of hirsutism: a randomized, double blind, placebo- controlled trial. J Clin Endocrinol Metab, Jan; 85 (1): 89- 94.

Nadia F. Soliman, \& Peter G. Wardle. (2006). The investigation and management of the hirsute women. Gynaecological and Perinatal Practice, 6: 145-152

Ricardio Azziz MD, MPH. (2003). The evaluation and management of hirsutism. Obstetrics \& Gynecology, Volume 101, Issue 5, Part 1: 955-1007.

Spritzer PM, Lisboa KO, Mattiello S, \& Lhullier F. (2000). Spironolactone as a single agent for long- term therapy of hirsute patients. Clin Endocrinology (Oxf), 52(5): 587-94.

Tremblay RR. (1986). Treatment of hirsutism with spironolactone. Clin Endocrinol Metab, 15 (2): 363 - 71.

Van Der Spuy ZM, \& Le Roux PA. (2003). Cyproterone acetate for hirsutism.Cochrane database Syst. Rev 2003; (4): CD001125.

Table 1. Distribution of studied sample according to personal and family history

\begin{tabular}{|l|l|l|}
\hline Variables & Number & Percentage \% \\
\hline Marital status & & \\
Married & 8 & 19.05 \\
Unmarried & 34 & 80.95 \\
\hline Family history of hirsutism & & \\
+ ve & 18 & 42.86 \\
- ve & 24 & 57.14 \\
\hline
\end{tabular}


Table 2. distribution of studied sample according to age, anthropometric measurement, and some characteristic related to hirsutism

\begin{tabular}{|l|l|l|l|l|}
\hline Variables & Mean & St. deviation & Minimum & Maximum \\
\hline Age $($ year $)$ & 27.7 & 5.12 & 18 & 39 \\
\hline BMI $\left(\mathrm{kg} / \mathrm{m}^{2)}\right.$ & 28.90 & 6.97 & 20.40 & 52 \\
\hline Duration of hirsutism (year) & 7.76 & 4.90 & 2 & 20 \\
\hline Score of hirsutism & 14.95 & 7.73 & 8 & 35 \\
\hline Testosterone level $(\mathrm{ngm} / \mathrm{ml})$ & 3.22 & 1.38 & 1.6 & 5.5 \\
\hline
\end{tabular}

Table 3. Distribution of studied sample according to plan of treatment

\begin{tabular}{|l|l|l|l|}
\hline Group & Plan of treatment & Number & Percentage\% \\
\hline I & Aldactone & 12 & 28.57 \\
\hline II & Aldactone + Metformin & 8 & 19.05 \\
\hline III & Aldactone + OCs & 16 & 38.10 \\
\hline IV & Aldactone + Metformin + OCs & 6 & 14.28 \\
\hline
\end{tabular}

Table 4. One way ANOVA demonstrating the statistical differences in mean hair shaft diameter among the four studied groups, at base line, 3 months and 6 months after treatment

\begin{tabular}{|l|l|l|l|l|}
\hline Groups & No. & $\begin{array}{c}\text { Mean hair shaft } \\
\text { diameter } \\
(\mu \mathrm{m})\end{array}$ & St. deviation & P value \\
\hline Base line & 12 & 66.67 & 17.75 & \\
I & 8 & 62.50 & 27.65 & 0.559 \\
II & 16 & 61.25 & 16.66 & \\
III & 6 & 53.33 & 5.16 & \\
IV & 12 & 36.67 & 7.78 & 0.446 \\
\hline 3 months after treatment & 8 & 42.50 & 13.89 & \\
I & 16 & 35.00 & 10.33 & \\
II & 6 & 40.00 & 15.49 & \\
III & 12 & 31.66 & 9.37 & \\
IV & 8 & 30.00 & 7.55 & \\
\hline 6 months after treatment & 16 & 23.75 & 8.85 & \\
I & 6 & 33.33 & 10.32 & \\
II & & & \\
III & IV &
\end{tabular}

Table 5. One way ANONA showing the statistical differences in mean diameter of hair shaft of all groups of the studied sample according to the level of treatment

\begin{tabular}{|l|l|l|l|}
\hline Level of treatment & $\begin{array}{c}\text { Mean diameter of hair } \\
\text { shaft } \\
(\mu \mathrm{m})\end{array}$ & St. deviation & P value \\
\hline $\begin{array}{l}\text { At base line } \\
\mathrm{n}=42\end{array}$ & 61.90 & 18.38 & \multirow{2}{*}{0.000} \\
$\begin{array}{l}3 \quad \text { months after } \\
\text { treatment } \\
\mathrm{n}=42\end{array}$ & 37.62 & 11.20 & \\
\hline $\begin{array}{l}6 \quad \text { months after } \\
\text { treatment } \\
\mathrm{n}=42\end{array}$ & 28.57 & 9.52 & \\
\hline
\end{tabular}


Table 6. The percentage of reduction in the mean diameter of hair shaft of the studied sample after 3 months according to the plan of treatment

\begin{tabular}{|l|l|l|l|l|l|l|}
\hline Group & $\begin{array}{c}\text { Base line } \\
\text { Mean } \\
\text { diameter } \\
(\mu \mathrm{m})\end{array}$ & $\begin{array}{c}\text { After 3 } \\
\text { months } \\
\text { Mean } \\
\text { diameter } \\
(\mu \mathrm{m})\end{array}$ & $\begin{array}{c}\text { Differences } \\
\text { in } \\
\text { Mean } \\
\text { diameter } \\
(\mu \mathrm{m})\end{array}$ & $\begin{array}{c}\text { \% } \\
\text { reduction }\end{array}$ & $\begin{array}{c}95 \% \\
\text { CI }\end{array}$ & P value \\
\hline $\begin{array}{l}\text { I } \\
\mathrm{n}=12\end{array}$ & 66.67 & 36.67 & 30.00 & 44.49 & $18.39 ; 41.61$ & 0.000 \\
\hline $\begin{array}{l}\text { II } \\
\mathrm{n}=8\end{array}$ & 62.50 & 42.50 & 20.00 & 32 & $-3.5 ; 43.5$ & 0089 \\
\hline $\begin{array}{l}\text { III } \\
\mathrm{n}=16\end{array}$ & 61.25 & 35.00 & 26.25 & 42.85 & $15.90 ; 35.85$ & 0.000 \\
\hline $\begin{array}{l}\text { IV } \\
\mathrm{n}=6\end{array}$ & 53.33 & 40.00 & 13.33 & 24.99 & $-1.52 ; 28.19$ & 0.073 \\
\hline
\end{tabular}

Table 7. The percentage of reduction in mean diameter of hair shaft of the studied sample after 6 months according to the plan of treatment

\begin{tabular}{|l|l|l|l|l|l|l|}
\hline Group & $\begin{array}{c}\text { Base line } \\
\text { Mean } \\
\text { diameter } \\
(\mu \mathrm{m})\end{array}$ & $\begin{array}{c}\text { After 6 months } \\
\text { Mean diameter } \\
(\mu \mathrm{m})\end{array}$ & $\begin{array}{c}\text { Differences } \\
\text { in Mean } \\
\text { diameter } \\
(\mu \mathrm{m})\end{array}$ & $\begin{array}{c}\% \\
\text { reduction }\end{array}$ & $\begin{array}{c}95 \% \\
\text { CI }\end{array}$ & P value \\
\hline $\begin{array}{l}\text { I } \\
\mathrm{n}=12\end{array}$ & 66.67 & 31.67 & 35.00 & 52.49 & $22.98 ; 47.02$ & 0.000 \\
\hline $\begin{array}{l}\text { II } \\
\mathrm{n}=8\end{array}$ & 62.50 & 30.00 & 32.50 & 51.2 & $10.80 ; 54.20$ & 0.006 \\
\hline $\begin{array}{l}\text { III } \\
\mathrm{n}=16\end{array}$ & 61.25 & 24.50 & 36.75 & 60.0 & $27.35 ; 46.15$ & 0.000 \\
\hline $\begin{array}{l}\text { IV } \\
\mathrm{n}=6\end{array}$ & 53.33 & 33.33 & 20.00 & 37.5 & $9.50 ; 30.50$ & 0.002 \\
\hline
\end{tabular}

